\title{
The effect of temperature on the phenotypic features and the maceration ability of Dickeya solani strains isolated in Finland, Israel and Poland
}

\author{
Malgorzata Golanowska • Joanna Kielar • \\ Ewa Lojkowska
}

Accepted: 15 September 2016 / Published online: 4 October 2016

(C) The Author(s) 2016. This article is published with open access at Springerlink.com

\begin{abstract}
Pectinolytic bacteria from the genus Dickeya (former Erwinia chrysanthemi), belonging to Dickeya dianthicola and Dickeya solani species, are causative agents of blackleg and soft rot diseases in Europe. Recently, D. solani have been isolated most frequently from potato plants with the symptoms of blackleg and soft rot. D. solani strains were shown to cause more severe disease symptoms on potato plants than D. dianthicola especially at the higher temperature. They are also able to develop blackleg disease from lower inoculum levels. In the presented study we not only compared phenotypic features of fifteen $D$. solani strains isolated in countries having different climatic conditions, Poland, Finland and Israel, but also we examined three D. dianthicola strains. The comparison was performed to determine the influence of the strain origin and the temperature of incubation on the ability of the strains to macerate potato tissue and on their major virulence factors such as: pectinolytic, cellulolytic and proteolytic activities, siderophore production and motility. Polish D. solani strains showed higher activities of cell wall degrading enzymes than the Finnish and Israeli strains at all the tested temperatures: $18,27,37^{\circ} \mathrm{C}$. This
\end{abstract}

Electronic supplementary material The online version of this article (doi:10.1007/s10658-016-1044-1) contains supplementary material, which is available to authorized users.

M. Golanowska · J. Kielar · E. Lojkowska $(\bowtie)$

Department of Biotechnology, Intercollegiate Faculty of

Biotechnology of University of Gdansk and Medical University of

Gdansk, 58 Abrahama Str., 80-307, Gdansk, Poland

e-mail: ewa.lojkowska@biotech.ug.edu.pl observation is correlated with the higher ability of Polish D. solani strains to cause soft rot. In addition, D. solani strains exhibited higher activity of the above mentioned enzymes and caused more severe potato tuber maceration in laboratory tests than the tested $D$. dianthicola strains. The collected results indicate that although $D$. solani strains from different climatic conditions have identical Pulse Field Gel Electrophoresis (PFGE) profiles in addition to the same fingerprint profiles obtained by the repetitive sequence-based polymerase chain reaction (REP, ERIC and BOX repetitive sequences), they differ in the examined phenotypic features, especially in the activities of pectinolytic, cellulolytic and proteolytic enzymes and their capacity to macerate potato tuber tissue.

Keywords Different climate $\cdot$ Pectinolytic bacteria . Plant cell-wall degrading enzymes · Rep-PCR · PFGE . Virulence factors

\section{Introduction}

Dickeya species (Samson et al. 2005), formerly named Pectobacterium chrysanthemi (Hauben et al. 1998) and Erwinia chrysanthemi (Burkholder et al. 1953), are causative agents of soft rot and blackleg in potato. Similarly to Dickeya species, Pectobacterium species, formerly called Erwinia carotovora (Burkholder et al. 1953), can cause blackleg and soft rot. The genus Dickeya is a highly diverse group, which according to the present classification contains eight species: D. aquatica, D. chrysanthemi, D. dadantii, D. 
dianthicola, D. fangzhongdai D. paradisiaca, D. solani and D. zeae (Samson et al. 2005; Brady et al. 2012; van der Wolf et al. 2014; Parkinson et al. 2014; Tian et al. 2016). Bacteria from this genus were known to cause disease symptoms, especially in tropical and subtropical climates, on a large number of host plant species, including many economically important crops like potato, maize and banana (Ma et al. 2007). Dickeya sp. strains isolated from potato plants outside of Europe fell into biovar 3 and 6 and possessed high optimum growth temperature. They were classified to $D$. dadanti, D. chrysanthemi or D. zeae species (Dickey 1981; Samson et al. 2005; Toth et al. 2011).

Dickeya strains that were firstly isolated from potato plants in Europe belonged to biovar 1 and 7, which coincide with $D$. dianthicola, a species adapted to cool regions (Cazelles and Schwarzel 1992; Janse and Ruissen 1988). During last decade, strains from $D$. solani species were isolated from potatoes across Europe and Israel (Toth et al. 2011; van der Wolf et al. 2014) undoubtedly more often than the strains of $D$. dianthicola. Laurila et al. (Laurila et al. 2008; Laurila et al. 2010) and Degefu et al. (2013) reported the presence of D. solani strains in Finland. Also, the strains of $D$. solani were isolated from potato plants with blackleg and soft rot symptoms in France, the Netherlands, Poland, Spain and Switzerland (Palacio-Bielsa et al. 2006; Helias 2006; Czajkowski et al. 2009; Slawiak et al. 2009a; b; Toth et al. 2011; Gill et al. 2014; Potrykus et al. 2016). Besides, Tsror et al. (Tsor (Lahkim) et al. 2009; Tsror (Lahkim) et al. 2013) isolated $D$. solani strains from blackleg diseased potato plants in Israel.

In the recent years, potato losses are caused, apart from the Dickeya strains, also by other pectinolytic bacteria known as tropical and subtropical pathogens, e.g. Pectobacterium wasabiae (Nabhan et al. 2012; Waleron et al. 2013), and Pectobacterium carotovorum subsp. brasiliense (de Werra et al. 2015, Nunes Leite et al. 2014, Waleron et al. 2015). These losses caused by the strains from the mentioned taxa increased significantly in a large number of European countries. We could hypothesize, that the fast spread of D. solani, P. wasabiae and P. c. subsp. brasiliense in Europe is connected with an increase in the spring and summer temperatures, arising as a consequence of the global warming and more intense international seed potato exchange.

Bacteria from species $D$. solani have a wider optimal temperature range for growth and soft rot disease development (from $25^{\circ} \mathrm{C}$ to $39^{\circ} \mathrm{C}$ ). They also possess features which allow for more effective colonization and faster spread through the plant vascular system than in the case of D. dianthicola (Czajkowski et al. 2010). All previously characterized $D$. solani strains indicated identical rep-PCR and PFGE profiles (Degefu et al. 2013; Tsror (Lahkim) et al. 2013; van der Wolf et al. 2014; Potrykus et al. 2016). However, the comparison of genome sequences of several $D$. solani strains indicated the existence of some differences within the studied strains caused probably by the horizontal gene transfer (Khayi et al. 2015).

Crucial factors for soft rot and blackleg symptoms development influencing the potato tissue maceration are, amongst other aspects, the growth rate of the pathogen, its capacity to produce plant cell-wall degrading enzymes (PCWDE) and its motility (HugouvieuxCotte-Pattat et al. 1996). The Dickeya group is characterized by the ability to produce pectinolytic enzymes, among which pectate lyases are considered as the most important virulence factors. Extracellular pectate lyases cause degradation of pectins and polygalacturonic acid, which are important components of the plant cell wall. Studies on a model strain D. dadantii 3937 indicated that the specific regulation of the pectinases expression and secretion depends on the temperature, humidity and the type of plant tissue (Hugouvieux-Cotte-Pattat et al. 1996; Hugouvieux-Cotte-Pattat and Charaoui-Boukerzaza 2009; Hugouvieux-Cotte-Pattat et al. 2014; KazemiPour et al. 2004). According to Hugovieux-Cotte-Pattat et al. (Hugouvieux-Cotte-Pattat et al. 1996) temperature is one of the most important external factors influencing the survival of $D$. dadantii 3937 in the environment. Temperature also modifies the growth rate and the metabolic activity of this pathogen and its ability to cause disease symptoms. However, little is known about the influence of environmental conditions on pectinolytic enzymes production and the aggressiveness of $D$. solani.

The question why $D$. solani has spread throughout Europe and caused more severe losses than $D$. dianthicola has been raised by researchers across Europe (Czajkowski et al. 2009; Toth et al. 2011; Degefu et al. 2013; Potrykus et al. 2016). Studies show that these pathogens are able to induce diseases at the lower inoculum levels, produce more PCWDE and in addition possess an arsenal of T5SS/T6SS secreted proteins exhibiting more diverse functions than just destroying the plant cell-wall (Toth et al. 2011; Garlant et al. 2013; Pedron et al. 2014; Khayi et al. 2015; Potrykus et al. 2016). 
Strains of $D$. solani are able to cause severe disease symptoms in a wide range of climates (for example in European countries like Finland, the Netherlands, Poland, France, or Switzerland, to a country such as Israel). Yet, there is only one comparative study performed on D. solani strains originating from different climate conditions (Tsror (Lahkim) et al. 2013). In the present study, we verified the genetic homogeneity of the strains of $D$. solani isolated in the previous years from infected potato plants under different temperature conditions (in Poland, Finland and Israel) and compared their phenotypic features such as pectinases, cellulases and proteases activities, siderophores production, potato tissue maceration, as well as their motility. The main goal of this study was to evaluate the effect of the origin of isolation (Finland, Israel, Poland), the incubation temperature $\left(18,28\right.$ and $\left.37^{\circ} \mathrm{C}\right)$ on the intensiveness of the tested features. The above shown temperatures were arbitrary chosen as typical for the summer months in cold, temperate and hot climate countries.

\section{Materials and methods}

Bacterial strains, media and culture conditions

D. solani strains isolated in Finland, Israel and Poland and strains from different Dickeya species used in this paper are listed in Table 1. Polish Dickeya solani isolates were obtained in 2005, 2009 and 2010 during routine procedures of isolating bacteria from infected seed potato

Table 1 Dickeya spp. strains used in this study

\begin{tabular}{|c|c|c|c|}
\hline Name & IFB number (other collections) & Country and year of isolation & Source, references \\
\hline Dickeya dadantii & IFB0010 $0^{\mathrm{a}, \mathrm{b}}\left(\mathrm{NCPPB} 98^{\mathrm{T}}, \mathrm{IPO}^{2120}\right)$ & Comoros, 1960 & Pelargonium capitatum Samson et al. 2005 \\
\hline Dickeya dadantii & IFB0016 ${ }^{\mathrm{c}}(3937, \mathrm{~A} 4922)$ & France & Sepolia ionantha Kotoujansky et al. 1982 \\
\hline Dickeya dianthicola & $\mathrm{IFB} 103^{\mathrm{a}}\left(\mathrm{NCPPB} 453^{\mathrm{T}}, \mathrm{IPO} 2114\right)$ & UK, 1956 & Dianthus caryophyllus Samson et al. 2005 \\
\hline Dickeya dianthicola & IFB0157 $7^{\mathrm{d}}(\mathrm{LMG} 28825)$ & Poland, 2009 & Solanum tuberosum This work \\
\hline Dickeya dianthicola & IFB0188 ${ }^{\mathrm{a}}(\mathrm{IPO} 1741)$ & The Netherlands, 1992 & Solanum tuberosum van der Wolf et al. 2014 \\
\hline Dickeya solani & IFB0123 ${ }^{\mathrm{a}}(\mathrm{IPO} 2222)$ & The Netherlands, 2007 & Solanum tuberosum Czajkowski et al. 2013 \\
\hline Dickeya solani & IFB0099 ${ }^{\mathrm{d}}$ (IPO2276, LMG28824) & Poland, 2005 & Solanum tuberosum Slawiak et al. 2009a, b \\
\hline Dickeya solani & IFB0100 ${ }^{\mathrm{d}}(\mathrm{IPO} 2277)$ & Poland, 2005 & Solanum tuberosum This work \\
\hline Dickeya solani & IFB0158 ${ }^{\mathrm{d}}$ (LMG 28826) & Poland, North 2009 & Solanum tuberosum Potrykus et al. 2014 \\
\hline Dickeya solani & IFB0167 & Poland, South-west 2009 & Solanum tuberosum Potrykus et al. 2016 \\
\hline Dickeya solani & IFB0212 ${ }^{\mathrm{d}}$ & Poland, Central 2010 & Solanum tuberosum This work \\
\hline Dickeya solani & IFB0231 ${ }^{\mathrm{e}}(\mathrm{VIC}-\mathrm{BL} 25)$ & Finland 2008 & Solanum tuberosum Degefu et al. 2013 \\
\hline Dickeya solani & IFB0236 ${ }^{\mathrm{e}}$ (VIC-SRI 5) & Finland 2008 & Solanum tuberosum Degefu et al. 2013 \\
\hline Dickeya solani & IFB0254 ${ }^{\mathrm{e}}(\mathrm{SRG} 5-4)$ & Finland 2008 & Solanum tuberosum Degefu et al. 2013 \\
\hline Dickeya solani & IFB0261 ${ }^{\mathrm{e}}(\mathrm{BLG} 4-5)$ & Finland 2008 & Solanum tuberosum Degefu et al. 2013 \\
\hline Dickeya solani & IFB0265 ${ }^{\mathrm{e}}(\mathrm{SRG} 54-4)$ & Finland 2008 & Solanum tuberosum Degefu et al. 2013 \\
\hline Dickeya solani & IFB0124 ${ }^{\mathrm{f}}(\mathrm{IPO} 3228)$ & Israel, 2008 & Solanum tuberosum Tsror (Lahkim) et al. 2013 \\
\hline Dickeya solani & IFB0125 f (IPO3296) & Israel, 2008 & Solanum tuberosum Tsror (Lahkim) et al. 2013 \\
\hline Dickeya solani & IFB0455 f (IPO3204) & Israel, 2007 & Solanum tuberosum Tsror (Lahkim) et al. 2013 \\
\hline Dickeya solani & IFB0456 ${ }^{\mathrm{f}}(\mathrm{IPO} 3213)$ & Israel, 2008 & Solanum tuberosum Tsror (Lahkim) et al. 2013 \\
\hline Dickeya solani & IFB0457 ${ }^{\mathrm{f}}($ IPO3236) & Israel, 2009 & Solanum tuberosum Tsror (Lahkim) et al. 2013 \\
\hline
\end{tabular}

\footnotetext{
${ }^{\mathrm{a}}$ J. Wolf, PRI, Wageningen, Holland

${ }^{\mathrm{b}}$ Toth, SCRI, Dundee, Scotland

${ }^{\mathrm{c}}$ N. Hugouvieux, MAP, INSA, Lyon, Francja

${ }^{\mathrm{d}}$ LPPB, Intercollegiate Faculty of Biotechnology UG and MUG, Gdansk Poland

e Yeshetila Degefu, Finland

${ }^{\mathrm{f}}$ Leah Tsror, Israel
} 
as reported by Potrykus et al. (2016). Five D. solani strains isolated in Finland were obtained by courtesy of Dr. Yeshitila Degefu, MTT Agrifood Research Finland, Biotechnology and Food Research, Agro Biotechnology University of Oulu, FI, Finland. Israeli strains were obtained by courtesy of Dr. Leah Tsror, Gilat Research Center, Israel (five strains) and Dutch strain (D. solani Type strain IPO2222) thanks to Dr. Jan. van der Wolf, Plant Research International, Wageningen.

All strains were stored in $40 \%$ glycerol at $-80{ }^{\circ} \mathrm{C}$. Bacteria were cultured in LB medium or LB supplemented with agar $15 \mathrm{~g} \mathrm{~L}^{-1}$ and/or CVP (Crystal Violet Pectate, Helias et al. 2012) at $28^{\circ} \mathrm{C}$ for $24-48 \mathrm{~h}$ prior to DNA extraction and performing the phenotypic and maceration ability tests. In the case of liquid preparations, bacterial cultures were grown in LB medium at $28^{\circ} \mathrm{C}$ with shaking (200 rpm).

Genetic characterization of $D$. solani strains from different climate conditions

\section{REP-PCR profiling}

Finish, Israeli and Polish strains of D. solani and the Type Strains of other Dickeya species (Table 1) were analyzed using the repetitive sequence based PCR (rep-PCR) with three sets of primers: ERIC 1R and ERIC 2 (Enterobacterial Repetitive Intergenic Consensus), REP 1 R-I and REP 2-I (Repetitive Extragenic Palindromic sequences) and also BOX1AIR as described by Versalovic et al. (Versalovic et al. 1991 and Versalovic et al. 1994), respectively. Genomic DNA was isolated using Genomic Mini AX Bacteria Kit (A\&A Biotechnology, Poland). The resulting products of amplification with REP, ERIC or BOX primers were separated by electrophoresis at $50 \mathrm{~V}$ for $2.5 \mathrm{~h}$ in $0.8 \%$ agarose (Basica, Prona) gel using $0.5 \mathrm{x}$ TBE buffer and visualized and documented using the Gel Doc imaging system (Bio Rad Laboratories Inc.) supported by Quantity One Software (Bio Rad Laboratories Inc., Hercules, CA, USA).

Restriction fragment length polymorphism - pulse field gel electrophoresis (RFLP-PFGE)

The RFLP - PFGE was performed as already described by Degefu et al. (2013). After the electrophoresis run was completed, the gels were stained with ethidium bromide solution $\left(0.5 \mathrm{mg} \mathrm{ml}^{-1}\right)$, rinsed with water, and the band pattern was observed under UV light. As a standard, Salmonella enterica serotype Braenderup (strain H9812, ATCC) was used.

D. solani growth curves determination

Determination of the growth dynamics was established in 48-well plates with the use of EnVision spectrophotometer plate reader (Perkin Elmer, USA) with orbital shaking at two temperatures: 28 and $37^{\circ} \mathrm{C}$. The night culture of each strain was diluted 1: 50 in fresh LB medium, reaching $500 \mu \mathrm{l}$ as the final volume of the culture. The measurement of the absorbance at $600 \mathrm{~nm}$ was performed every hour for $20 \mathrm{~h}$. The experiment with two replicates was performed twice.

Qualitative phenotypic analyses - plate assays

For plate tests, a bacterial suspension containing $10^{8} \mathrm{cfu} \mathrm{ml}^{-1}$ was prepared and $2 \mu \mathrm{l}$ was spotted on a plate and incubated for $48 \mathrm{~h}$, unless otherwise stated. All experiments were performed at three different temperatures: 18, 28 and $37{ }^{\circ} \mathrm{C}$. The experiments with two replicates were performed three times.

Pectinase activity was tested on plates with M63Y PGA medium (Reverchon et al. 1986). After $24 \mathrm{~h}$ incubation plates were covered with $10 \%$ copper acetate solution. Copper acetate reacts with PGA, giving the blue color of medium. If bacteria degrade PGA there is a whitish halo around bacterial colonies. The halo diameter is in proportion to the activity of pectinases.

Cellulase activity was analyzed on M63 agar plates supplemented with glycerol at $2 \mathrm{~g}$ liter $^{-1}$ and carboxymethylcellulose at $10 \mathrm{~g} \mathrm{l}^{-1}$, as described by Wood (1980). After incubation the plates were flooded with Congo Red solution $\left(10 \mathrm{mg} \mathrm{ml}^{-1}\right)$ for $10 \mathrm{~min}$ and washed for $5 \mathrm{~min}$ with $1 \mathrm{M} \mathrm{NaCl}$. The diameter of the clear halo around the colonies was measured. The halo diameter indicated the activity of cellulases.

Protease activity was measured on medium supplemented with skim milk (12.5 $\mathrm{g} \mathrm{l}^{-1}$ ) (Ji et al. 1987). The diameter of the clear halo around the colonies was measured. The halo diameter is in proportion to the activity of produced proteases.

Siderophore production and an ability to chelate iron ions were determined on chrome azurol S-agar plates (Schwyn and Neilands 1987). The diameter of the orange halo around the colonies was measured.

Motility assay. To assess the swimming motility bacterial strains were inoculated onto $0.3 \%$ semisolid 
agar plates (Harshey 2003) and incubated for $24 \mathrm{~h}$. The diameter of the colonies was measured.

Quantitative evaluation of pectate lyases activities

For measurements of the total pectate lyase activity, bacteria were grown in M63 medium (Miller 1972) supplemented with glycerol (Y) to the final concentration of $2 \%$ (noninduced conditions) or glycerol and poligalacturonic acid (PGA, Sigma) (induced conditions) to the final concentration of 2 and $0.2 \%$, respectively. The bacteria were cultivated up to the stationary phase $(24 \mathrm{~h})$ in aerobic conditions at $28^{\circ} \mathrm{C}$ with shaking (200 rpm).

The assay medium contained PGA $0.05 \%, 0.1 \mathrm{mM}$ $\mathrm{CaCl}_{2}, 100 \mathrm{mM}$ Tris- $\mathrm{HCl} \mathrm{pH}$ 8.5. This $\mathrm{pH}$ was chosen as optimal for majority of pectate lyase (HugouvieuxCotte-Pattat et al. 2014). Pectate lyase activity (PL) was determined by spectrophotometric monitoring of the ability to form unsaturated products, which absorb light at $235 \mathrm{~nm}$ (Tardy et al. 1997). Bacterial cultures were grown to the stationary phase $(24 \mathrm{~h})$. One unit of pectate lyases activity was defined as the amount of enzyme required to produce $1 \mu \mathrm{mol}$ of unsaturated product per $1 \mathrm{~min}$. Total pectate lyases activity was expressed as $\mu$ moles of unsaturated products liberated per min per mg of bacterial dry mass. The experiment with three replicates was performed three times.

\section{Maceration ability test}

Potatoes cv. Lord, average tuber size 60-70 mm were washed under running water and sterilized with $10 \%$ of commercially available bleach (i.e. ACE or Clorox) for $20 \mathrm{~min}$. Later on, tubers were thoroughly washed in water. Tubers were dried under the laminar flow. Dried tubers were cut aseptically crosswise into $10 \mathrm{~mm}$ thick slices. Slices were placed in glass Petri dishes $(150 \mathrm{~mm} \times 25 \mathrm{~mm})$ containing a layer of Whatman filter paper. Depending on the slice size, two or three holes $5 \times 5 \mathrm{~mm}$ were cut in the surface of the slices. Into each hole $50 \mu$ l of bacterial suspension was added. Whatman filter paper in each Petri dish was moistened with $5 \mathrm{ml}$ of sterile water. Potato slices were inoculated with three different level of bacteria $\left(10^{5}, 10^{6}\right.$ and $10^{7} \mathrm{cfu} \mathrm{ml}^{-1}$ ). Bacterial suspensions were prepared in $0.85 \% \mathrm{NaCl}$. Inoculated slices were incubated at $28^{\circ} \mathrm{C}$ for $48 \mathrm{~h}$ and the diameter of rotten tissue was measured. As a negative control $50 \mu \mathrm{l}$ of $0.85 \% \mathrm{NaCl}$ was used. The experiment with nine replicates was repeated twice.
Statistical analysis

Statistica 12 ® (StatSoft Inc., USA) was used to analyze data related to phenotypic traits of Dickeya spp. strains (enzymatic activities, siderophore production and swimming motility in relation to temperature, also pectinolytic activity test and ability to macerate potato tuber slices). For the dataset of enzymatic activities, siderophores production and motility, a two-way analysis of variance (ANOVA) was performed where 'origin of strain' or 'species' and 'temperature' were used as the experimental factors. For the dataset of total pectinolytic activity, a two-way ANOVA was conducted with 'origin of strain' or 'species' and 'conditions' taken as the experimental factors. For the dataset of ability to macerate potato tuber slices the two-way ANOVA was conducted with 'origin of strain' and 'inoculation level' as the experimental factors. The impacts of the origin/ species and the temperature on tested phenotypic traits were derived from the one-way ANOVA models as the determination coefficients (presented in percentages).

\section{Results}

Molecular profiling of D. Solani strains from different climatic conditions

Two molecular profiling techniques: rep-PCR and RFLPPFGE were used to characterize the genomic material of D. solani strains isolated in Poland, Finland and Israel. The results of fingerprinting indicated that genomic profiles of all tested $D$. solani strains were the same regardless of the profiling method used (Fig. 1). Profiles of D. solani from Poland, Finland and Israel have the same molecular pattern as D. solani IPO $2222^{\mathrm{TS}}$ (IFB0123). At the same time they do differ from the profiles of D. dadantii (strains IFB0010 ${ }^{\mathrm{TS}}$ and IFB0016) and D. dianthicola (strains IFB0103 ${ }^{\mathrm{TS}}$ and IFB0157).

Dickeya sp. growth dynamic

All the tested $D$. solani strains have a similar growth dynamic. At $28^{\circ} \mathrm{C}, D$. solani ${ }^{\mathrm{TS}}$ strain reaches the stationary phase after the same time as D. dadantii ${ }^{\mathrm{TS}}$ (after $12 \mathrm{~h}$ ), earlier than Polish, Finnish, Israeli strains of D. solani and D. dianthicola ${ }^{\mathrm{TS}}(13.8 \mathrm{~h}, 15.6 \mathrm{~h}, 12.8 \mathrm{~h}$ and $14 \mathrm{~h}$, respectively). At $37^{\circ} \mathrm{C} \mathrm{D}$. dianthicola ${ }^{\mathrm{TS}}$ reaches stationary phase most rapidly (after $12 \mathrm{~h}$ ), earlier 

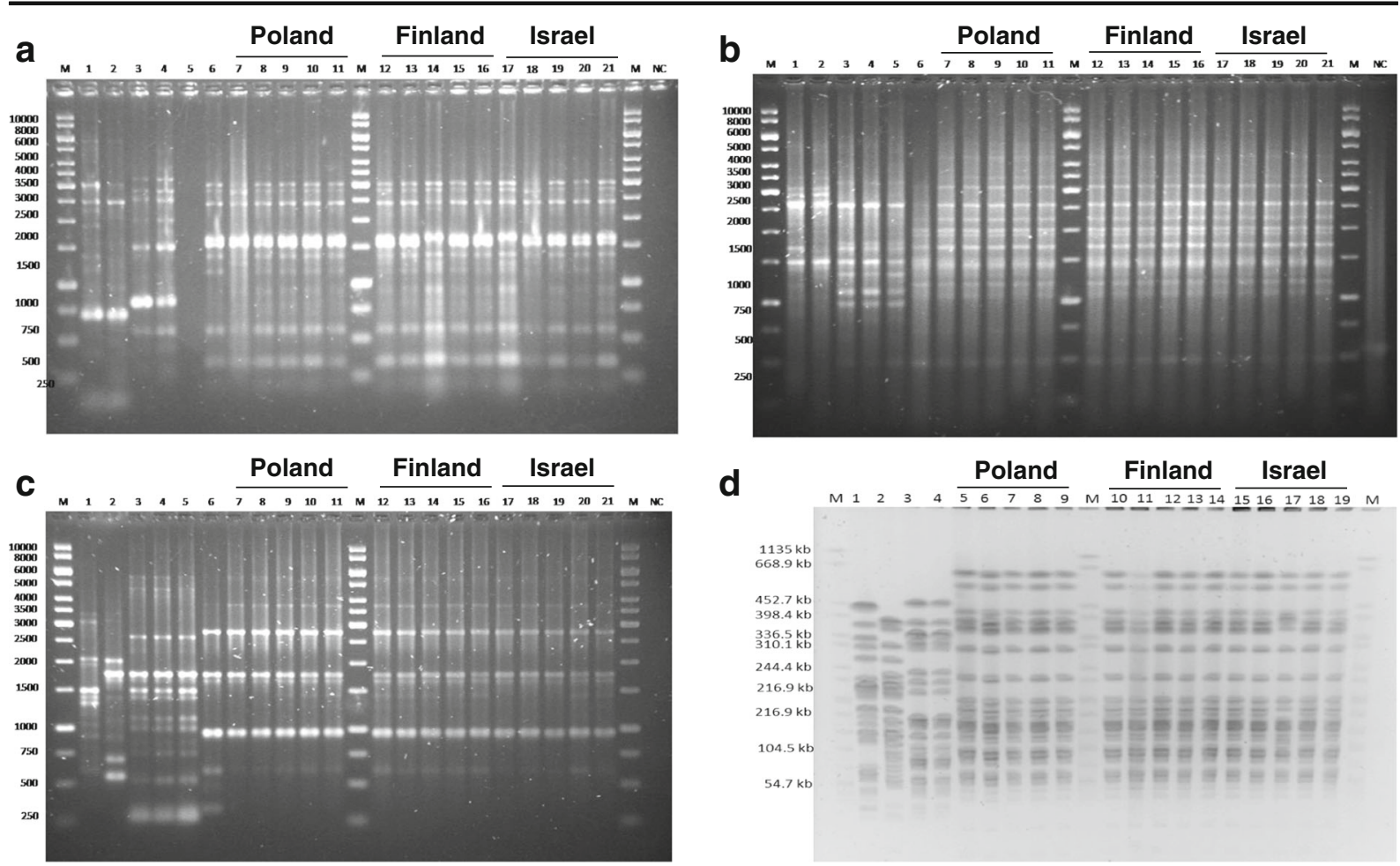

d

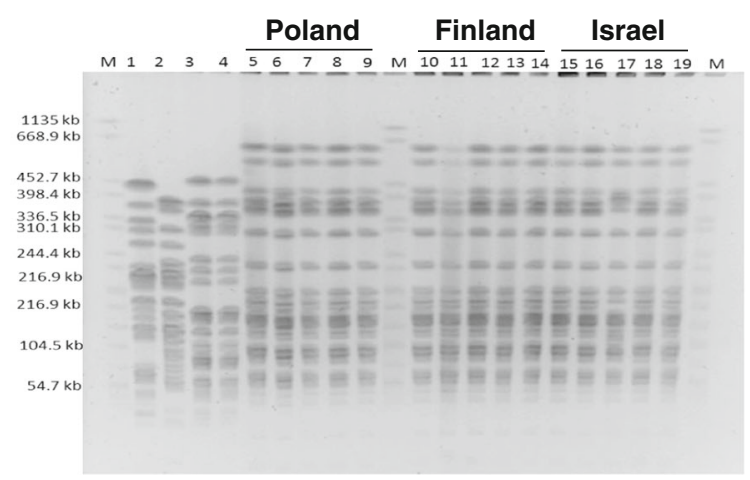

Fig. 1 Genetic homogeneity of tested $D$. solani strains evaluated by rep-PCR and RFLP-PFGE profiling. a REP PCR profiling, $\mathbf{b}$ BOX PCR profiling, $\mathbf{c}$ ERIC PCR profiling. For panels $\mathbf{a}, \mathbf{b}$ and $\mathbf{c}$ the order is as follows: $1-D$. dadantii IFB0010; $2-D$. dadantii IFB0016; 3 - D. dianthicola IFB0103; 4 - D. dianthicola IFB0157; 5 - D. dianthicola IFB0188; 6. D. solani ${ }^{\text {TS }}$ - IPO2222; Poland: 7 IFB0099; 8 - IFB0100; 9 - IFB0158; 10 - IFB0167; 11 - IFB0212; Finland: 12 - IFB0231; 13 - IFB0236; 14 - IFB0254; 15 IFB0261; 16 - IFB0265; Israel: 17 - IFB0124; 18 - IFB0125; 19

than D. dadantii $(13 \mathrm{~h})$ and $D$. solani $^{\mathrm{TS}}(16 \mathrm{~h})$. Interestingly, at $37{ }^{\circ} \mathrm{C}$ Polish strains grew to the stationary phase more quickly than the Finnish and Israeli ones: $14.8 \mathrm{~h}$ in comparison to 15.6 and $16 \mathrm{~h}$, respectively (Table 2).

The statistical analysis of the time of entering the stationary phase as well as the level of the maximum optical density reached at $28{ }^{\circ} \mathrm{C}$ and at $37{ }^{\circ} \mathrm{C}$ did not allow to distinguish significant differences in growth dynamics between strains of $D$. solani originating from different climatic conditions, nor between different Dickeya species (one-way ANOVA, $p>0.05$ ).

Phenotypes of $D$. solani strains originating from different climatic conditions

Strains originating from Poland are the most homogenous group, within the group of Finnish strains there is

- IFB0455; 20 - IFB0456; 21 - IFB0457. d PFGE profiling, 1 D. dadantii IFB0010; 2 - D. dadantii IFB0016; 3 - D. dianthicola IFB 0157; 4 - D. dianthicola IFB0188; No. from 5 to 19: D. solani. Poland: 5 - IFB0099; 6 - IFB 0100; 7 - IFB0158; 8 - IFB0167; 9 IFB0212; Finland: 10 - IFB0231; 11 - D. solani IFB0236; 12 IFB0254; 13 - IFB0261; 14 - IFB0265; Israel: 15 - IFB0124; 16 IFB0125; 17 - IFB0455; 18 - IFB0456; 19 - IFB0457; M - marker Salmonella enterica ser. Braenderup DNA digested with XbaI

usually one strain exhibiting lower enzymatic activities, while the Israeli strains are the most diverse, especially regarding enzymatic activities and the ability to swim (Supplement 1). All tested Dickeya strains have the highest enzymatic activities at $28^{\circ} \mathrm{C}$. Polish $D$. solani strains exhibit the highest pectinolytic, cellulolytic and proteolytic activities at this temperature (Fig. 2). They differ significantly from the Israeli strains in all tested temperatures. The enzymatic activity of Finnish D. solani strains comprises between the levels determined for Polish and Israeli strains.

Israeli strains indicated the highest siderophores pruduction (ability to chelate iron ions) at $28{ }^{\circ} \mathrm{C}$, but not at 18 and $37^{\circ} \mathrm{C}$. The Finnish strains did not differ significantly from the Israeli and the Polish ones (Fig. 2). Besides, Polish and Finnish strains indicated significantly better ability to swim at $28{ }^{\circ} \mathrm{C}$, then Israeli strains, but at other temperatures differences were not significant (Fig. 2). 
Table 2 Growth of $D$. solani strains at $28^{\circ} \mathrm{C}$ and $37^{\circ} \mathrm{C}$ in comparison to $D$. dadantii and $D$. dianthicola

\begin{tabular}{|c|c|c|c|c|c|}
\hline \multirow[t]{2}{*}{ Dickeya spp. } & & \multicolumn{2}{|c|}{ Time to achieve maximum density $[\mathrm{h}]$} & \multicolumn{2}{|c|}{ Maximal optical density } \\
\hline & & $28^{\circ} \mathrm{C}$ & $37^{\circ} \mathrm{C}$ & $28^{\circ} \mathrm{C}$ & $37^{\circ} \mathrm{C}$ \\
\hline \multirow[t]{6}{*}{ D. solani from Poland } & IFB0099 & 14 & 15 & 0.92 & 0.86 \\
\hline & IFB0100 & 15 & 13 & 0.90 & 0.87 \\
\hline & IFB0158 & 13 & 14 & 0.84 & 0.89 \\
\hline & IFB0167 & 14 & 16 & 0.88 & 0.77 \\
\hline & IFB0212 & 13 & 16 & 0.82 & 0.80 \\
\hline & Average & 13.8 & 14.8 & 0.87 & 0.84 \\
\hline \multirow[t]{6}{*}{ D. solani from Finland } & IFB0231 & 16 & 16 & 0.68 & 0.85 \\
\hline & IFB0236 & 16 & 13 & 0.64 & 0.50 \\
\hline & IFB0254 & 15 & 16 & 0.81 & 0.79 \\
\hline & IFB0261 & 16 & 16 & 0.79 & 0.85 \\
\hline & IFB0265 & 15 & 16 & 0.82 & 0.94 \\
\hline & Average & 15.6 & 15.4 & 0.75 & 0.78 \\
\hline \multirow[t]{6}{*}{ D. solani from Israel } & IFB0124 & 10 & 16 & 0.86 & 0.71 \\
\hline & IFB0125 & 16 & 16 & 0.73 & 0.86 \\
\hline & IFB0455 & 15 & 16 & 0.87 & 0.68 \\
\hline & IFB0456 & 13 & 16 & 0.59 & 0.51 \\
\hline & IFB0457 & 10 & 16 & 0.90 & 0.84 \\
\hline & Average & 12.8 & 16 & 0.79 & 0.72 \\
\hline \multicolumn{2}{|c|}{ D. solani IPO 2222, IFB0123 } & 12 & 16 & 0.77 & 0.87 \\
\hline \multicolumn{2}{|c|}{$\begin{array}{l}\text { Mean value for all } 16 \text { tested } \\
\text { D. solani strains }\end{array}$} & 13.9 & 14.4 & 0.80 & 0.77 \\
\hline \multicolumn{2}{|c|}{ D. dadantii $\mathrm{NCPPB} 898^{\mathrm{T}}$ IFB0010 } & 12 & 13 & 0.79 & 0.79 \\
\hline \multicolumn{2}{|c|}{$\begin{array}{l}\text { D. dianthicola } \mathrm{NCPPB} 43^{\mathrm{T}} \\
\text { IFB } 0103\end{array}$} & 14 & 12 & 0.85 & 0.91 \\
\hline
\end{tabular}

Phenotypes of strains from different Dickeya species

The two strains of $D$. dadantii and three strains of $D$. dianthicola were compared with the $D$. solani ${ }^{\mathrm{TS}}$ chosen arbitrarily as a representative. In general, all the strains irrespective of their species have highest pectinolytic, cellulolytic and proteolytic activities at $28{ }^{\circ} \mathrm{C}$ (Fig. 3). At this temperature $D$. dadantii and D. solani have similar pectinolytic and cellulolytic activities. D. dianthicola has significantly lower pectinolytic and cellulolytic activities than two other species. However, at $37{ }^{\circ} \mathrm{C}$ $D$. dadantii has significantly higher pectinolytic activity than $D$. solani and $D$. dianthicola (in the case of $D$. dianthicola the activity is close to 0 ), while at $18{ }^{\circ} \mathrm{C} D$. solani possesses the highest pectinolytic activity (similar to the one of $D$. dadantii at $37^{\circ} \mathrm{C}$ ). D. solani indicated the highest proteolytic activity at 18 and $28{ }^{\circ} \mathrm{C}$ (Fig. 3). Concerning the production of siderophores and the swimming ability, no significant differences were observed between the temperature of incubation and the strains tested except of the significantly higher siderophores production by $D$. dadantii strains at $37{ }^{\circ} \mathrm{C}$ (Fig. 3).

Total pectinolytic activity of Dickeya strains in induced and noninduced conditions

Conditions in which D. solani is grown has a significant impact on the total pectinolytic activity especially when evaluated by monitoring spectrophotometrically the formation of unsaturated products from polygalacturonate. In induced conditions (media supplemented with PGA) at $28{ }^{\circ} \mathrm{C}$, all strains of $D$. solani have significantly higher (5 
Fig. 2 Comparison of the plant cell wall degrading enzymes activities of $D$. solani strains originating from different countries at 18,28 and $30^{\circ} \mathrm{C}$. Pol - mean value for five Polish D. solani strains: IFB0099, IFB0100, IFB0158, IFB0167, IFB0212; Fin - mean value of halo diameter for five Finnish strains: IFB0231, IFB0236, IFB0254, IFB0261, IFB0265; Is mean value of halo diameter for five Israeli strains: IFB0124, IFB0125, IFB0455, IFB0456, IFB0457. Error bars represent standard error from three experimental repetitions. Columns with different letters are significantly different when twoway ANOVA followed by post hoc Tukey test at $p<0.001$ with the $F$ values indicated as follows: pectinases $F=3.927, n=2$; cellulases $F=6.717, \mathrm{n}=2$; proteases $F=5.422, \mathrm{n}=2$; siderophores $F=14.981, \mathrm{n}=2$; swimming $F=24.62, n=2$
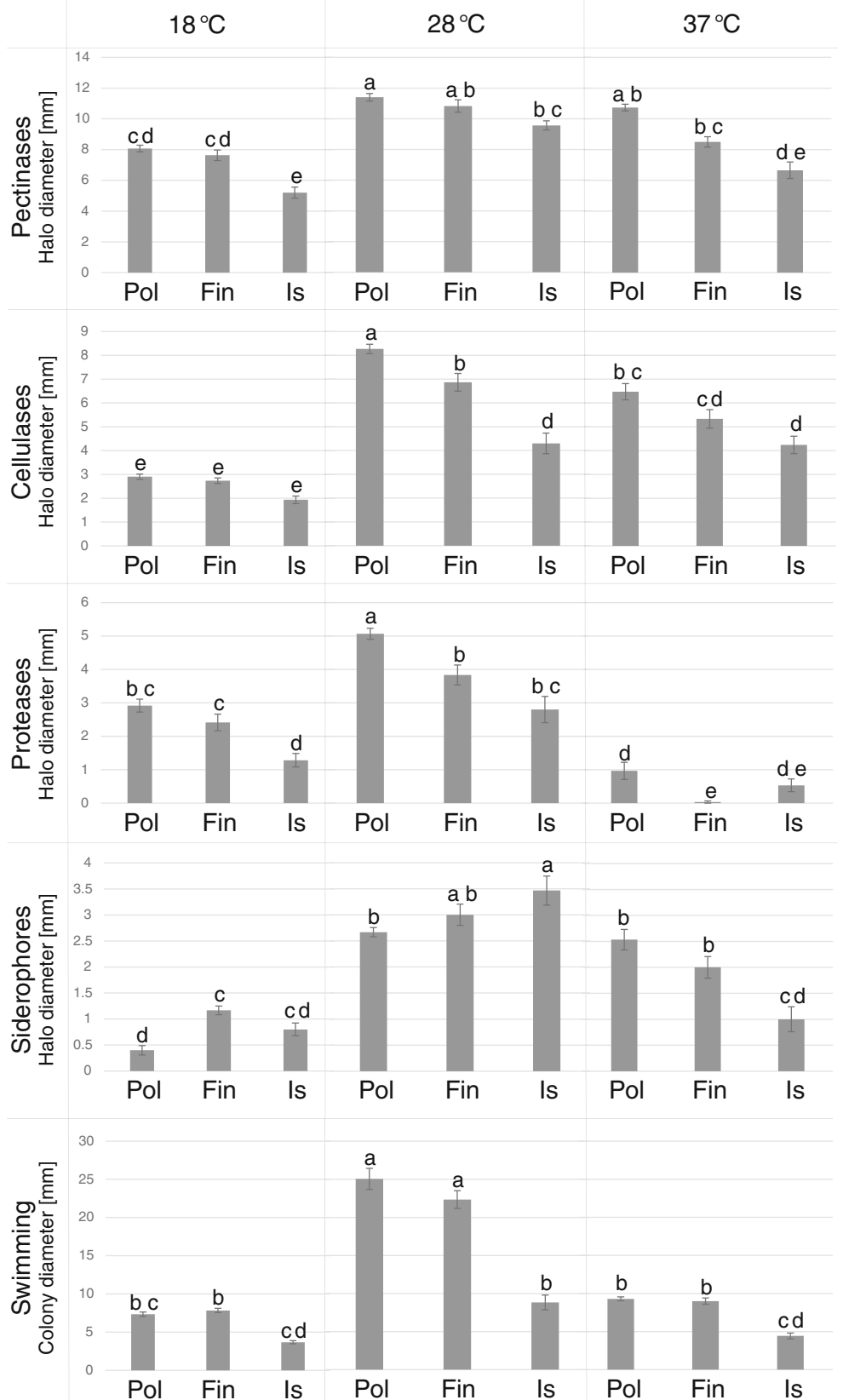

to 10 times) pectinolytic activity than in noninduced conditions (Fig. 4a, Supplement 2). In non-induced conditions the Polish strains have higher pectinolytic activity than the Finnish and the Israeli strains. Also, in induced conditions strains originating from different countries vary significantly from each other. Also in the induced conditions, Polish strains exhibit the highest pectinolytic activity, while the value for Finnish strains fell between the activities determined for Polish and Israeli strains.

The presence of PGA in the incubation medium also influenced the pectinolytic activity of strains from $D$. dadantii species. D. dadantii and $D$. solani strains have significantly higher pectinolytic activity than D. dianthicola in both non-induced and induced 
Fig. 3 Plant cell wall degrading enzymes activities, siderophore production and swimming motility of different Dickeya spp. at at 18,28 and $30^{\circ} \mathrm{C}$. Dd D. dadantii, mean value of halo diameter for two strains: IFB0010 and IFB0016, Ddia -

D. dianthicola, mean value of halo diameter for three strains: IFB0103, IFB0157 and IFB0188, $\mathrm{Ds}^{\mathrm{TS}}-$ D. solani IPO2222 (IFB0123). Error bars represent standard error from three experimental repetitions.

Columns with different letters are significantly different when twoway ANOVA followed by post hoc Tukey test at $p<0.001$ with the $F$ values indicated as follows: pectinases $F=23.488, \mathrm{n}=2$; cellulases $F=13.623, \mathrm{n}=2$; proteases $F=221.045, \mathrm{n}=2$, siderophores $F=14.077, \mathrm{n}=2$. For swimming the statistical analysis did not distinguish any significant differences $(p>0.001$, $\mathrm{n}=2$ )

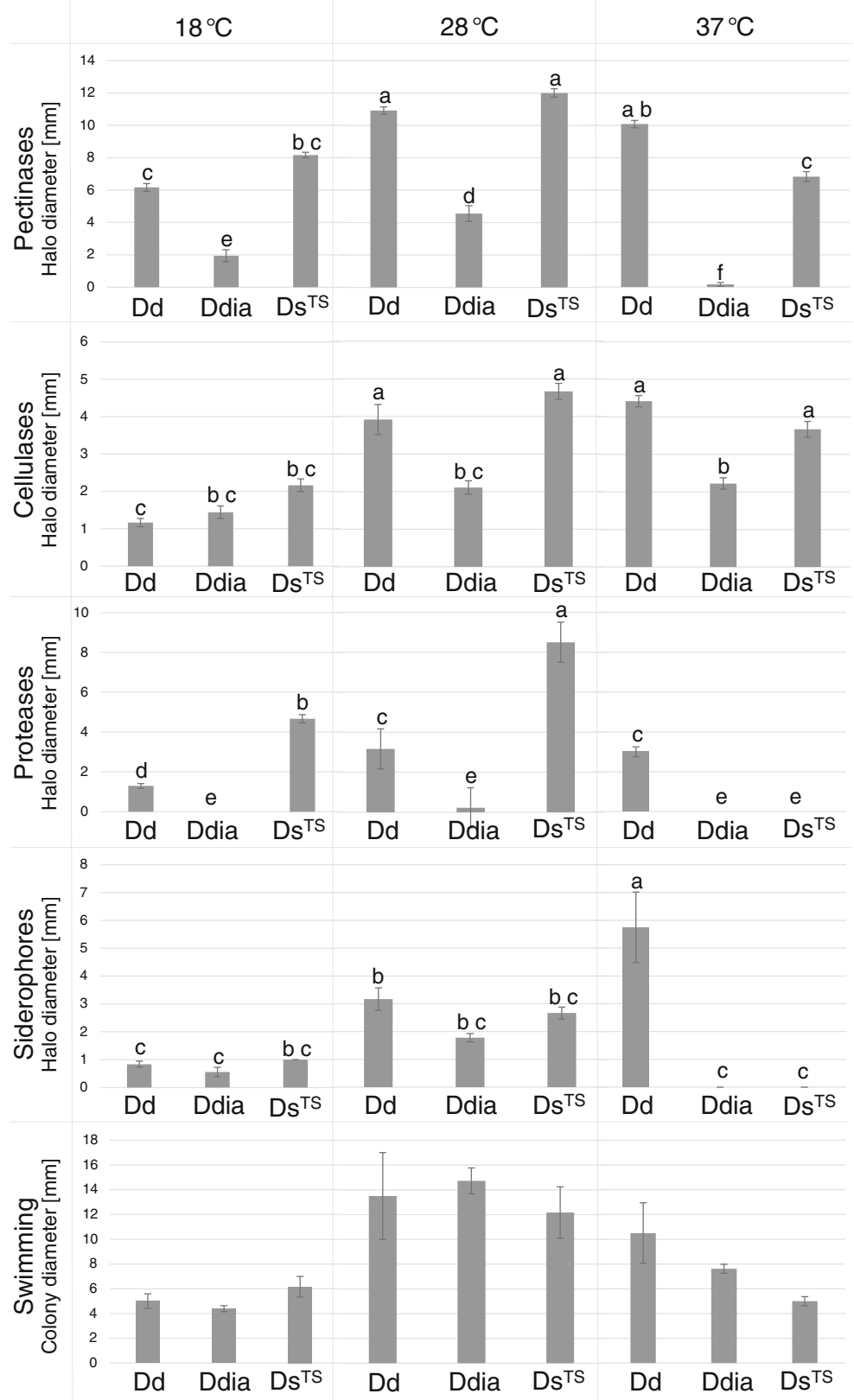

conditions (Fig. 4 B). D. solani indicated higher pectinolytic activity than $D$. dadantii.

Ability to macerate potato tissue by D. Solani from different climatic conditions

Potato slices were inoculated with the bacterial suspensions containing $10^{5}, 10^{6}$ and $10^{7} \mathrm{cfu} \mathrm{ml}^{-1}$ and incubated at $28^{\circ} \mathrm{C}$ for $48 \mathrm{~h}$. Some variability in the ability to macerate potato tissue was observed among Finish and Israeli strains but not the Polish ones (Supplement 3). The analysis did not distinguish the significance of the inoculum level along with the origin of the D. solani strains. However, Polish D. solani strains are able to macerate potato tissue more efficiently than the strains from 


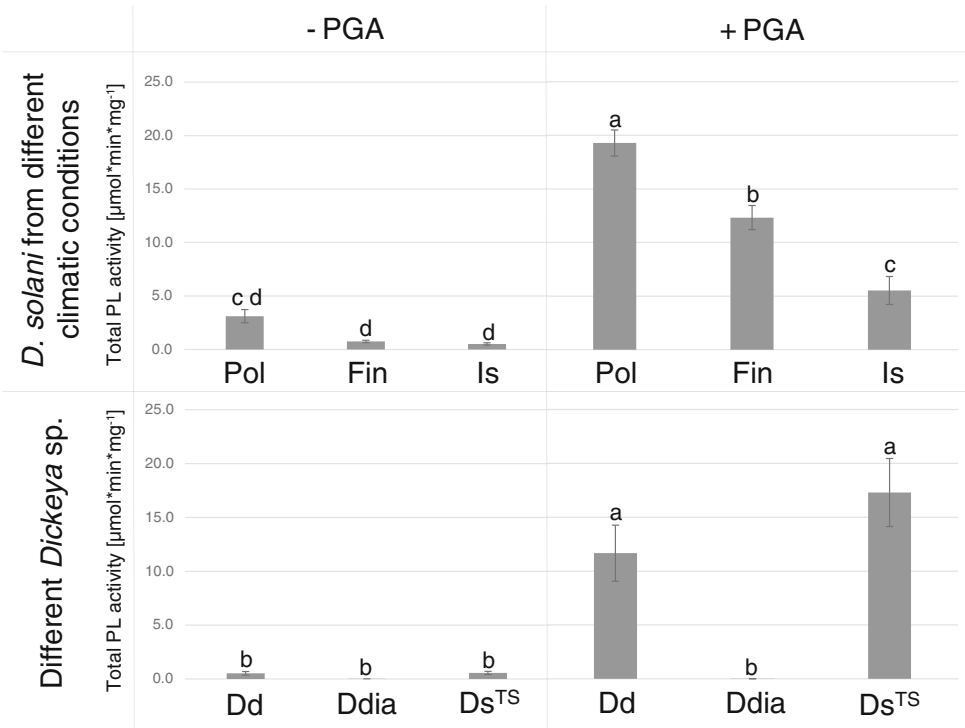

Fig. 4 Comparison of the total pectinolytic activity of tested Dickeya strains. a $D$. solani strains of different origin in noninduced (-PGA) and induced (+PGA) conditions. b strains from different Dickeya species. Dd $-D$. dadantii, mean value of halo diameter for two strains: IFB0010 and IFB; Ddia - D. dianthicola, mean value of halo diameter for three strains: IFB0103, IFB0157 and IFB0188; Ds $^{\text {TS }}$ - D. solani IPO2222 (IFB0123); Pol - mean value of halo diameter for five Polish $D$. solani strains: IFB0099, IFB0100, IFB0158, IFB0167, IFB0212; Fin - mean value of halo

Finland or Israel at all tested inoculum levels (Fig. 5, Supplement 3). We did not observe any rotting on slices inoculated with the negative diameter for five Finnish strains: IFB0231, IFB0236, IFB0254, IFB0261, IFB0265; Is - mean value of halo diameter for five Israeli strains: IFB0124, IFB0125, IFB0455, IFB0456, IFB0457. Error bars represent standard error from three experimental repetitions. Columns with different letters are significantly different when two-way ANOVA followed by post hoc Tukey test at $\mathrm{p}<0.001$ with the $\mathrm{F}$ values indicated as follows: upper panel $\mathrm{F}=7.833, n=3$; lower panel $\mathrm{F}=19.432, n=3$

control, so we excluded the possibility of presence of a latent pectinolityc bacteria other than tested inocula.

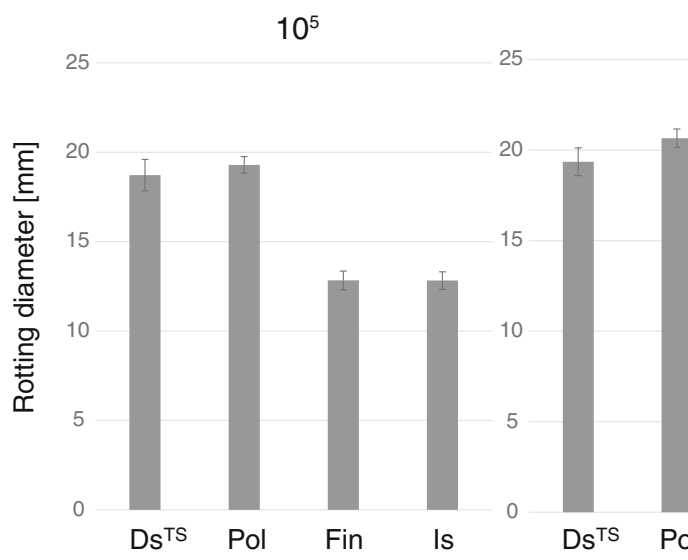

Fig. 5 Comparison of the maceration of potato tuber tissue by D. solani strains isolated in different climatic conditions. $\mathrm{Ds}^{\mathrm{TS}}$ D. solani Type Strain IPO2222; Pol - mean value of halo diameter for five Polish D. solani strains: IFB0099, IFB0100, IFB0158, IFB0167, IFB0212; Fin - mean value of halo diameter for five Finnish strains: IFB0231, IFB0236, IFB0254, IFB0261, IFB0265;
$10^{6}$

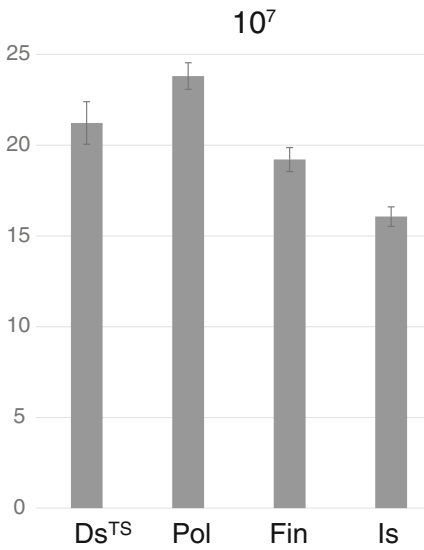

Is - mean value of halo diameter for five Israeli strains: IFB0124, IFB0125, IFB0455, IFB0456, IFB0457. Error bars represent standard error from two experimental repetitions. Statistical analysis by two-way ANOVA followed by post hoc Tuckey test did not distinguish any significant differences $(p>0.001, n=9)$ 
The role of species, origin and temperature on phenotypic traits expression

Performed statistical analysis showed that for enzymatic activities such as pectinases, proteases as well as the ability to chelate iron ions, the species of the strain has higher impact than the temperature of incubation (Table 3a). In the case of pectinases production, the species impact can explain $69 \%$ of the variation. The effect of species also explains $52 \%$ of variability in proteases production and $23 \%$ of variation in the iron chelating ability. On the other hand, the influence of the temperature explains only $15 \%$ of the pectinolytic activity variability and only $1 \%$ of variance both for proteases production and the ability to chelate iron ions. Only for the cellulases activity and the swimming ability the incubation temperature has higher impact on these traits than has the effect of the species, with the temperature explaining $34 \%$ and $32 \%$ of described variability, respectively.

As regards the geographical origin of the strains (country from which $D$. solani strains were isolated), the temperature had higher impact on the exhibited traits (pectinolytic - $30 \%$, cellulolytic - $41 \%$, proteolytic $47 \%$ activities as well as the swimming motility $-47 \%$ and the ability to chelate iron ions $-44 \%$ ) than the origin itself (Table $3 b$ ). The effect of the climatic origin

Table 3 The importance of the species, the geographical origin of the strain and the temperature of incubation on the ability to produce different PCWDE (pectinases, cellulases and proteases) and ability to produce siderophores and swimming expressed in percent's. A The importance of the species and temperature. B. The importance of the geographical orgin and the temperature

\begin{tabular}{cll} 
A & & \\
Factors & Species & Temperature \\
Pectinases & 69 & 15 \\
Cellulases & 25 & 34 \\
Proteases & 52 & 1 \\
Siderophores & 23 & 1 \\
Swimming & 0 & 32 \\
B & & \\
Factors & Geographical origin & Temperature \\
Pectinases & 20 & 30 \\
Cellulases & 14 & 41 \\
Proteases & 1 & 47 \\
Siderophores & 0,1 & 44 \\
Swimming & 20 & 47 \\
\hline
\end{tabular}

of the strains on total pectinolytic activity in induced conditions explains $30 \%$ of the variability. Concerning the ability to macerate potato tissue, the origin of the strains played a more important role than the inoculums level ( $21 \%$ and $1 \%$, respectively).

\section{Discussion}

The emergence of new, virulent Dickeya strains in Europe has become a big problem for the producers of seed potatoes as well as for the farmers producing the ware crop. At the same time, there are no methods of curing the disease and all protection is based on prevention methods, especially important is planting the pathogen-free potato seeds. Of similar significance is testing seed potatoes for the presence of soft rotting bacteria before selling and exporting the seed lots. In the previous years, because of this reason, a zero tolerance policy was introduced in Scotland for Dickeya spp. on potato crops (Toth et al. 2011). In Israel, the recent disease outbreaks observed on potatoes grown from tubers imported from the European countries are of great concern, thus their causative agent, D. solani, is considered as a quarantine organism in this country (Tsror (Lahkim) et al. 2013).

Still little is known about the biology, virulence mechanisms and epidemiology of $D$. solani. Genomic analysis of $D$. solani has stated that this species is most closely related to $D$. dadantii 3937 strain (94\% ANI), (Garlant et al. 2013; Pedron et al. 2014; van der Wolf et al. 2014). This is fortunate, because this strain of D. dadantii appears to be the best studied in the terms of molecular determinants of virulence and its regulators. A multitude of molecular techniques have been developed to study $D$. dadantii 3937 . Potrykus et al. (2014) adapted the techniques used for D. dadantii 3937 mutagenesis and applied them in the research on $D$. solani. The major transcriptional regulators of $D$. dadantii $3937 \mathrm{KdgR}, \mathrm{PecS}$, and PecT play a similar role in the regulation of virulence in D. solani; they act as the negative regulators of several genes encoding factors involved in the virulence (Potrykus et al. 2014). This study indicates also that the thermoregulator PecT is an essential regulator of $D$. solani virulence.

The present study of $D$. solani strains originating from different climatic conditions indicated that all of them represent identical rep-PCR and RFLP-PFGE 
profiles. This finding confirms the results of Degefu et al. (2013) and van der Wolf et al. (2014), that also indicated high similarities between $D$. solani strains of different origin. The variable tandem repeats method applied by Parkinson et al. (2015) has revealed low variability among 54 tested $D$. solani strains. What is more, 4 out of 16 D. solani strains tested in this study (D. solani ${ }^{\mathrm{TS}}$ IPO2222, Polish IFB0099, Israeli IFB0124 and Israeli IFB0125) have been analyzed by Parkinson et al. (2015). They discovered that D. solani ${ }^{\mathrm{TS}}$ has a different VNTR profile than three others from the above mentioned strains. However, the observed difference is present only in one locus out of the five tested. Parkinson et al. (2015) stated that the limited variation in VNTR profiles of $D$. solani may reflect a limited number of $D$. solani introductions and/or the short time period since the pathogen's first emergence in Europe. In the same study, 19 VNTR profiles of 45 $D$. dianthicola strains have been distinguished which means that $D$. dianthicola is much more variable than D. solani (Parkinson et al. 2015).

In the presented work we tried to answer the question whether observed differences in phenotypic features can be explained by the influence of geographical origin (Poland, Finland and Israel) or the growth temperature $\left(18,28\right.$ and $\left.37^{\circ} \mathrm{C}\right)$. In Poland and Finland, climate is temperate and rather cold (according to Koeppen described in Pidwirny 2006) and it only differs in regard to the summer, which in Poland is temperate and in Finland is shorter and colder. How does it relate to the hot and semi-arid climate in Israel with hot summer? Works of Degefu et al. (2013) and Potrykus et al. (2016) stated that there is an influence of climate change in terms of D. solani outbreaks in Finland and Poland. They suggested that the prevalence of Dickeya spp. is higher when the summer is hotter and dry. The climate change in the years 1976-2006 shows that the mean temperature values increased in the range of 0.4 to $1.0^{\circ} \mathrm{C}$ per decade in Poland and Finland, respectively. The prediction of annual temperature increase in Europe is between 0.3 and $0.35{ }^{\circ} \mathrm{C}$ for Poland and Finland respectively, as reported by the European Environmental Agency in 2015 (http://www.eea.europa.eu/data-and-maps/ figures/decadal-average-trends-in-mean-5).

According to our results D. solani strains indicate phenotypic variability apart from their genotypic homogeneity. The analysis of several phenotypic features of fifteen $D$. solani strains originating from three countries with different climatic conditions - Poland, Finland and
Israel - indicated differences in the PCWDE production, the swimming ability and in their ability to macerate potato tissue. Among the tested strains, Polish isolates indicated the lowest phenotypic variability (Supplementary materials 1, 2, 3) and the highest pectinolytic, cellulolytic and proteolytic activities at 18,28 and $37^{\circ} \mathrm{C}$ in addition to the highest ability to macerate potato tissue regardless of the inoculum level. Tsror (Lahkim) et al. (2013) observed the opposite effect. They stated that $D$. solani strains isolated in Israel are more virulent than those isolated in Europe. It can be explained by the fact that Tsror (Lahkim) et al. (2013) tested 22 Israeli strains of $D$. solani, we analyzed only five and two of these were isolated from seed potatoes imported to Israel. On the other hand, Tsror (Lahkim) et al. (2013) used only one strain isolated in Poland, namely IFB0099 (IPO2276), and a few strains isolated in the Netherlands, but none originating from Finland.

Polish strains also had the highest total pectate lyases activity estimated spectrophotometrically. In our studies four out of five Israeli strains exhibited low pectate lyase activity in the applied conditions. On the other hand, the work of Tsror (Lahkim) et al. (2013) indicated that the strains isolated in Israel had the highest expression of pectate lyase. Observable difference between these reports could be explained by the different methodology that was applied for the estimation of the pectate lyases activities. First of all, we estimated in this study the sum of the activities of several pectate lyases (PelA, PelB, PelC, PelD, PelE, PelL, PelN, PelX), while Tsror evaluated only the expression of pelL gene. Secondly, in the presented work bacteria were grown on M63 Y minimal medium supplemented with PGA as an inducer of the expression of genes encoding pectinolytic enzymes, whereas in the work of Tsror (Lahkim) et al. (2013) the expression of pelL gene was estimated for the bacteria grown in the macerated potato tubers. Former studies performed on $D$. dadantii 3937 showed that different pectate lyases are unequally induced by PGA and other components of the plant tissue (Jafra et al. 1999; Hugouvieux-Cotte-Pattat et al. 2014). Pectate lyases are divided into main and secondary pectate lyases and they are differently regulated. For example the expression of genes encoding the main pectate lyases PelD and PelE are principally induced by PGA, while the expression of genes encoding the secondary pectate lyase PelL is induced by both, PGA and the plant extract (Jafra et al. 1999, Golanowska, not published).

Our studies indicated that the strains' geographical origin (different climates) was less important than the 
temperature of incubation, when taking into account the impact of these two variables on the activities of PCWDE. The data presented here reveal significant impact of the genus of bacteria on the level of expression of the genes encoding for pectinases and proteases; D. solani strains exhibited higher PCWDE activities and better abilities to cause disease symptoms than $D$. dianthicola. This could explain the phenomenon of $D$. solani having highest chance to cause disease outbreaks when present in the ecological niche together with the other strains from Dickeya sp. However, our study includes only 3 strains of $D$. dianthicola, species that is known for high variability.

D. solani strains have higher pectinolytic, cellulolytic and proteolytic activities than the strains of D. dianthicola at almost all the tested temperatures and the highest total pectate lyases activities at $28{ }^{\circ} \mathrm{C}$. This could explain the fact that the strains of $D$. solani are better fitted to induce disease symptoms than D. dianthicola. Czajkowski et al. (2013) compared $D$. solani to $D$. dianthicola strains and also showed that $D$. solani possesses features which allow for more efficient potato plant colonization than in the case of D. dianthicola, especially at $28^{\circ} \mathrm{C}$. This suggests that D. solani could be a stronger competitor in the potato ecosystem. In the greenhouse experiments performed at $28{ }^{\circ} \mathrm{C}$, potato roots were more rapidly colonized by $D$. solani than by $D$. dianthicola and 30 days after inoculation higher densities of $D$. solani were found in the stolons and in the progeny tubers. In tubers coinoculated by vacuum infiltration with GFP-tagged D. solani and DsRed-tagged D. dianthicola, D. solani strain outcompeted $D$. dianthicola (Czajkowski et al. 2010). Moreover, D. solani indicated susceptibility only to $31 \%$ of saprophytic bacteria, potential biocontrol agents, when $D$. dianthicola indicated susceptibility to $80 \%$ of the tested strains (the selection included strains from the species such as: Serratia plymuthica, Pseudomonas spp., Delftia acidovorans, Pantoea agglomerans, Delftia acidovorans, Rahnella sp., Klebsiella sp. and Acinetobacter sp. (Czajkowski et al. 2010)).

In conclusion, our study showed that $D$. solani strains are genetically homogenous, but they exhibit phenotypic differences. Moreover, D. solani strains have higher plant cell-wall degrading enzymes activities (such as pectinases, cellulases and proteases) than $D$. dianthicola strains, regardless of the temperature of incubation. Besides, Polish D. solani strains are superior to strains originating from Finland and Israel in the production of PCWDE and their ability to macerate potato tissue.

Acknowledgments We thank Dr. Yashitila Degefu from Natural Resources Institute Finland, University of Oulu, Finland, Dr. Leah Tsror from Gilat Research Center, Israel and Dr. Jan. van der Wolf from Plant Research International, Wageningen, The Netherlands, for providing us with the strains isolated in Finland and in Israel. This work was financed by the National Science Centre, Poland 2013/08/M/NZ9/00974 to E. Lojkowska This work was also supported by the EU, ESF within the framework of the HCOP, Action 4.1.2, LiSMIDoS and by InnoDoktorant - Scholarships for $\mathrm{PhD}$ students, 6th edition to M. Golanowska. We would like to thank A. Motyka for the English corrections.

Open Access This article is distributed under the terms of the Creative Commons Attribution 4.0 International License (http:// creativecommons.org/licenses/by/4.0/), which permits unrestricted use, distribution, and reproduction in any medium, provided you give appropriate credit to the original author(s) and the source, provide a link to the Creative Commons license, and indicate if changes were made.

\section{References}

Brady, C. L., Cleenwerck, I., Denman, S., Venter, S. N., Rodriguez-Palenzuela, P., Coutinho, T. A., \& De Vos, P. (2012). Proposal to reclassify Brenneria quercina (Hildebrand and Schroth 1967) Hauben et al. 1999 into a new genus, Lonsdalea gen. nov., as Lonsdalea quercina comb. nov., descriptions of Lonsdalea quercina subsp. quercina comb. nov., Lonsdalea quercina subsp. iberica subsp. nov. and Lonsdalea quercina subsp. britannica subsp. nov., emendation of the description of the genus Brenneria, reclassification of Dickeya dieffenbachiae as Dickeya dadantii subsp. dieffenbachiae comb. nov., and emendation of the description of Dickeya dadantii. International Journal of Systematic and Evolutionary Microbiology, 62, 15921602.

Burkholder, W. H., MacFadden, L. H., \& Dimock, A. H. (1953). A bacterial blight of chrysanthemums. Phytopathology, 43, 522-525.

Cazelles, O., \& Schwarzel, R. (1992). Enquete sur les bacterrioses causes par Erwinia dans les cultures de plantes de pomme de terre en Suisse romande. Revue Suisse d'Agriculture., 24, 215-218.

Czajkowski, R., Grabe, G. J., \& van der Wolf, J. M. (2009). Distribution of Dickeya sp. and Pectobacterium subsp. carotovorum carotovorum in naturally infected seed potatoes. European Journal of Plant Pathology, 125, 263-275.

Czajkowski, R., de Boer, W. J., Velvis, H., \& van der Wolf, J. M. (2010). Systemic colonization of potato plants by soil-borne, GFP-tagged strain of Dickeya sp. biovar 3. Phytopathology, 100, 134-142.

Czajkowski, R., de Boer, W. J., van der Zouwen, P. S., Kastelein, P., Jafra, S., de Haan, E. G., van den Bovenkamp, G. W., \& 
van der Wolf, J. M. (2013). Virulence of 'Dickeya solani' and Dickeya dianthicola biovar-1 and -7 strains on potato (Solanum tuberosum). Plant Pathology, 62, 597-610.

de Werra, P., Bussereau, F., \& Keiser, A. (2015). First Report of Potato Blackleg Caused byPectobacterium carotovorum subsp. brasiliense in Switzerland. Plant Diseases, 99, 551.

Degefu, Y., Potrykus, M., Golanowska, M., Virtanen, E., \& Lojkowska, E. (2013). A new clade of Dickeya spp. plays a major role in potato blackleg outbreaks in North Finland. Annals of Applied Biology, 162, 231-241.

Dickey, R. S. (1981). Erwinia chrysanthemi: reaction of eight plant species to strains from several hosts and strains of other Erwinia species. Phytopathology, 71, 23-29.

Garlant, L., Koskinen, P., Rouhiainen, L., Laine, P., Paulin, L., Auvinen, P., Holm, L., \& Pirhonen, M. (2013). Genome sequence of Dickeya solani, a new soft rot pathogen of potato, suggests its emergence may be related to a novel combination of non-ribosomal peptide/polyketide synthetase clusters. Diversity, 5, 824-842.

Gill, E. D., Schaerer, S., \& Dupuis, B. (2014). Factors impacting blackleg development caused by Dickeya spp. in the field. European Journal of Plant Pathology, 140, 317-327.

Harshey, R. M. (2003). Bacterial motility on a surface: many ways to a common goal. Annual Review of Microbiology, 57, 249273.

Hauben, L., Moore, E. R. B., Vauterin, L., Steenackers, M., Mergaert, J., Verdonck, L., \& Swings, J. (1998). Phylogenetic position of phytopathogens within the Enterobacteriaceae. Systematic and Applied Microbiology, 21, 384-397.

Helias, V. (2006). Potato blackleg in France: Incidence of causal Erwinia species and field symptoms expression, 1st International Erwinia Workshop, 7th-9th July. Scotland: Dundee.

Hélias V., Hamon P., Huchet E., van der Wolf J.M. \& Andrivon D. (2012). Two new effective semiselective crystal violet pectate media for isolation of Pectobacterium and Dickeya. Plant Pathology, 61, 339-345.

Hugouvieux-Cotte-Pattat, N., \& Charaoui-Boukerzaza, S. (2009). Catabolism of raffinose, sucrose, and melibiose in Erwinia chrysanthemi 3937. Journal of Bacteriology, 191, 69606967.

Hugouvieux-Cotte-Pattat, N., Condemine, G., Nasser, W., \& Reverchon, S. (1996). Regulation of pectinolysis in Erwinia chrysanthemi. Annual Review of Microbiology, 50, 213-257.

Hugouvieux-Cotte-Pattat, N., Condemine, G., \& Shevchik, V. E. (2014). Bacterial pectate lyases, structural and functional diversity. Environmental Microbiology Reports, 6(5), 427440.

Jafra, S., Figura, I., Hugouvieux-Cotte-Pattat, N., \& Lojkowska, E. (1999). Expression of Erwinia chrysanthemi pectinase genes pelI, pelL, and pelZ during infection of potato tubers. Molecular Plant-Microbe Interactions, 10, 845-851.

Janse, J., \& Ruissen, M. (1988). Characterization and classification of Erwinia chrysanthemi strains from several hosts in The Netherlands. Phytopathology, 78, 800-808.

Ji, J., Hugouvieux-Cotte-Pattat, N., \& Robert-Baudouy, J. (1987). Use of Mu-lac insertions to study the secretion of pectate lyases by Erwinia chrysanthemi. Journal of General Microbiology, 133, 793-802.
Kazemi-Pour, N., Condemine, G., \& Hugouvieux-Cotte-Pattat, N. (2004). The secretome of the plant pathogenic bacterium Erwinia chrysanthemi. Proteomics, 10, 3177-3186.

Khayi, S., Blin, P., Pédron, J., Chong, T. M., Chan, K. G., Moumni, M., Hélias, V., Van Gijsegem, F., \& Faure, D. (2015). Population genomics reveals additive and replacing horizontal gene transfers in the emerging pathogen Dickeya solani. BMC Genomics, 2015(16), 788-801.

Kotoujansky, A., Lemattre, M., \& Boistard, P. (1982). Utilization of a thermosensitive episome bearing transposon Tn10 to isolate Hfr donor strains of Erwinia carotovora subsp. chrysanthemi. Journal of Bacteriology, 150, 122-131.

Laurila, J., Ahola, V., Lehtinen, A., Joutsjoki, T., Hannukkala, A., Rahkonen, A., \& Pirhonen, M. (2008). Characterization of Dickeya strains isolated from potato and river water samples in Finland. European Journal of Plant Pathology, 122, 213225.

Laurila, J., Hannukkala, A., Nykyri, J., Pasanen, M., Hélias, V., Garlant, L., \& Pirhonen, M. (2010). Symptoms and yield reductions caused by Dickeya species strains isolated from potato and river water in Finland. European Journal of Plant Pathology, 126, 249-262.

Leite, L. N., De Haan, E. G., Krijger, M., Kastelein, P., van der Zouwen, P. S., van den Bovenkamp, G. W., Tebaldi, N. D., \& van der Wolf, J. M. (2014). First report of potato blackleg caused by Pectobacterium carotovorum subsp. brasiliensis in the Netherlands. New Diseases Reports, 29, 24.

Ma, B., Hibbing, M. E., Kim, H.-S., Reedy, R. M., Yedidia, I., Breuer, J., Breuer, J., Glasner, J. D., Perna, N. T., Kelman, A., \& Charkowski, A. O. (2007). Host range and molecular phylogenies of the soft rot enterobacterial genera Pectobacterium and Dickeya. Phytopathology, 97, 11501163.

Miller, J. H. (1972). Experiments in Molecular Genetics. Cold Spring Harbor. New York: Cold Spring Harbor Laboratory Press.

Nabhan, S., Wydra, K., Linde, M., \& Debener, T. (2012). The use of two complementary DNA assays, AFLP and MLSA, for epidemic and phylogenetic studies of pectolytic enterobacterial strains with focus on the heterogeneous species Pectobacterium carotovorum. Plant Pathology, 61, 498-508.

Palacio-Bielsa, A., Cambra, M. A., \& López, M. M. (2006). Characterisation of potato isolates of Dickeya chrysanthemi in Spain by a microtitre system for biovar determination. Annals of Applied Biology, 148, 157-164.

Parkinson, N., DeVos, P., Pirhonen, M., \& Elphinstone, J. (2014). Dickeya aquatica sp. nov., isolated from waterways. International Journal of Systematic and Evolutionary Microbiology, 64, 2264-2266.

Parkinson, N., Pritchard, L., Bryant, R., Toth, I., \& Elphinstone, J. (2015). Epidemiology of Dickeya dianthicola and Dickeya solani in ornamental hosts and potato studied using variable number tandem repeat analysis. European Journal of Plant Pathology, 141(1), 63-70.

Pedron, J., Mondy, S., des Essarts, Y. R., Van Gijsegem, F., \& Faure, D. (2014). Genomic and metabolic comparison with Dickeya dadantii 3937 reveals the emerging Dickeya solani potato pathogen to display distinctive metabolic activities and T5SS/T6SS-related toxin repertoire. BMC Genomics, $15,283$. 
Pidwirny, M. (2006). Climate classification and climatic regions of the world. Fundamentals of Physical Geography, 2.

Potrykus, M., Golanowska, M., Hugouvieux-Cotte-Pattat, N., \& Lojkowska, E. (2014). Regulators involved in Dickeya solani virulence, genetic conservation, and functional variability. Molecular Plant-Microbe Interactions, 27, 700-711.

Potrykus, M., Golanowska, M., Sledz, W., Zoledowska, S., Motyka, A., Kolodziejska, A., Butrymowicz, J., \& Lojkowska, E. (2016). Biodiversity of Dickeya spp. isolated from potato plants and water sources in temperate climate. Plant Disease, 100, 408-417.

Reverchon, S., Van Gijsegem, F., Rouve, M., Kotoujansky, A., \& Robert-Baudouy, J. (1986). Organization of a pectate lyase gene family in Erwinia chrysanthemi. Gene, 49, 215-224.

Samson, R., Legendre, J. B., Christen, R., Saux, M. F. L., Achouak, W., \& Gardan, L. (2005). Transfer of Pectobacterium chrysanthemi (Burkholder et al. 1953) Brenner et al. 1973 and Brenneria paradisiaca to the genus Dickeya gen. nov. As Dickeya chrysanthemi comb. nov. and Dickeya paradisiaca comb. nov. And delineation of four novel species, Dickeya dadantii sp. nov., Dickeya dianthicola sp. nov., Dickeya dieffenbachiae sp. nov. and Dickeya zeae sp. International Journal of Systematic and Evolutionary Microbiology, 55, 1415-1427.

Schwyn, B., \& Neilands, J. B. (1987). Universal chemical assay for the detection and determination of siderophores. Analytical Biochemistry, 160, 47-56.

Slawiak, M., Lojkowska, E., \& van der Wolf, J. M. (2009a). First report of bacterial soft rot on potato caused by Dickeya spp. (syn. Erwinia chrysanthemi) in Poland. Plant Pathology, 58, 794.

Slawiak, M., van Beckhoven, J. R. C. M., Speksnijder, A. G. C. L., Czajkowski, R., Grabe, G., \& van der Wolf, J. M. (2009b). Biochemical and genetic analysis reveal a new clade of biovar 3 Dickeya spp. strains isolated from potato in Europe. European Journal of Plant Pathology, 125, 245261.

Tardy, F., Nasser, W., Robert-Baudouy, J., \& Hugouvieux-CottePattat, N. (1997). Comparative analysis of the five major Erwinia chrysanthemi pectate lyases: enzyme characteristics and potential inhibitors. Journal of Bacteriology, 179, 25032511.

Tian, Y., Zhao, Y., Yuan, X., Yi, J., Fan, J., Xu, Z., Hu B., De Boer S.H. \& Li, X. (2016). Dickeya fangzhongdai sp. nov., a plant- pathogenic bacterium isolated from pear trees (Pyrus pyrifolia). International Journal of Systematic and Evolutionary Microbiology. doi: 10.1099/ijsem.0.001060

Toth, I. K., van der Wolf, J. M., Saddler, G., Lojkowska, E., Helias, V., Pirhonen, M., Tsror Lahkim, L., \& Elphinstone, J. G. (2011). Dickeya species: an emerging problem for potato production in Europe. Plant Pathology, 60, 385-399.

Tsor (Lahkim), L., Erlich, O., Lebiush, S., Hazanovsky, M., \& Zig, U. (2009). Assessment of recent outbreaks of Dickeya sp. (syn. Erwinia chrysanthemi) slow wilt in potato crops in Israel. European Journal of Plant Pathology, 123, 311-320.

Tsror (Lahkim), L., Ben-Daniel, B., Chalupowicz, L., van der Wolf, J. M., Lebiush, S., Erlich, O., Dror, O., Barel, V., Nijhuis, E., \& Manulis-Sasson, S. (2013). Characterization of Dickeya strains isolated from potato grown under hot-climate conditions. Plant Pathology, 62, 1097-1105.

van der Wolf, J. M., Nijhuis, E. H., Kowalewska, M. J., Saddler, G. S., Parkinson, N., Elphinstone, J. G., Pritchard, L., Toth, I. K., Lojkowska, E., Potrykus, M., Waleron, M., de Vos, P., CleenWerck, I., Pirhonen, M., Garlant, L., Helias, V., Pothier, J. F., Pflüger, V., Duffy, B., Tsror, L., \& Manulis, S. (2014). Dickeya solani sp. nov., a pectinolytic plant pathogenic bacterium isolated from potato (Solanum tuberosum). International Journal of Systematic and Evolutionary Microbiology, 64, 768-774.

Versalovic, J., Koeuth, T., \& Lupski, R. (1991). Distribution of repetitive DNA sequences in eubacteria and application to fingerprinting of bacterial genomes. Nucleic Acids Research, 19, 6823-6831.

Versalovic, J., Schneider, M., De Bruijn, F. J., \& Lupski, J. R. (1994). Genomic fingerprinting of bacteria using repeti- tive sequence-based polymerase chain reaction. Methods in Molecular and Cellular Biology, 5, 25-40.

Waleron, M., Waleron, K., \& Lojkowska, E. (2013). Occurrence of Pectobacterium wasabiae in potato field samples. European Journal of Plant Pathology, 137, 149-158.

Waleron, M., Waleron, K., \& Lojkowska, E. (2015). First report of Pectobacterium carotovorum subsp. brasiliense causing soft rot on potato and other vegetables in Poland. Plant Disease, 99, 1271-1272.

Wood, P. J. (1980). Specificity in the interaction of direct dyes with polysaccharides. Carbohydrate Research, 85, 271-287. 